\title{
CHEST INJURIES ACCOMPANYING BLUNT SPINAL TRAUMA
}

\author{
๑ Hasan Oğuz Kapıcıbașı1', ๑ Ümit Ali Malçok²
}

\author{
${ }^{1}$ Çanakkale Onsekiz Mart University Faculty of Medicine, Department of Thoracic Surgery, Çanakkale, Turkey \\ ${ }^{2}$ Çanakkale Onsekiz Mart University Faculty of Medicine, Department of Neurosurgery, Çanakkale, Turkey
}

\begin{abstract}
Objective: Only a few studies in the literature have evaluated chest injuries accompanying blunt spinal trauma. We aimed to evaluate chest injuries observed concomitantly with spine injuries as well as reveal their clinical importance.

Materials and Methods: Eighty-eight patients, who were treated and followed up by the authors after being admitted to the emergency department because of severe blunt spinal trauma, were evaluated retrospectively.

Results: Data from a total of 55 patients [30 (54.5\%) male and 25 (45.5\%) female] who met the study criteria were included. The mean age of patients was $58 \pm 15$. Falling from height was the most common cause of trauma in 32 patients $(58.2 \%)$ and was significantly more frequent than other causes such as traffic accident, assault, non-vehicle traffic accident, and motorcycle accident ( $<<0.001)$. Spinal fracture was observed in 38 patients with severe blunt spinal trauma (69.1\%), while ligament and other soft tissue damage was found in 17 patients (30.9\%). Spinal fractures were significantly more frequent in the thoracic vertebra $(n=28 ; 50.9 \%)$ compared to other regions such as the cervical and lumbar spine $(p<0.001)$. It was observed that chest injury accompanied $33(60 \%)$ patients who experienced blunt spinal trauma. When the thoracic region was classified as per injured tissues; rib fracture $(n=10 ; 30.3 \%)$ and pulmonary contusion ( $n=6 ; 18.2 \%)$ were observed most frequently.

Conclusion: Patients with thoracic spinal fractures should be considered at a high risk for chest injury, and this group of patients should be prioritized because of the possible life-threatening complications. In our study, we concluded that the rate of falling from height increased in the elderly group, as well as neurological losses. Moreover, the rate of neurological deficit following thoracic vertebral damage due to falling from height kept increasing, especially in the elderly group.

Keywords: Spine injury, vertebral body fracture, chest injury
\end{abstract}

\section{INTRODUCTION}

Traumas are major causes of morbidity and mortality ${ }^{(1)}$. In addition to spine injuries detected in $23.2 \%$ of post-trauma cases, $4.4 \%$ of patients had thoracic or lumbar vertebral fractures ${ }^{(2,3)}$. Injury to the spine does not always develop as an isolated trauma. An injury to the adjacent organs, which can cause life-threatening complications, increases the complexity of the trauma of this region ${ }^{(4)}$. Approximately $65 \%$ of thoracolumbar fractures are caused by motor vehicle accidents and falls from height, while others are due to blows and sports injuries ${ }^{(5)}$. Spine injuries caused by a high-energy trauma are accompanied by serious tissue injuries, such as rib fractures, pneumothorax, hemothorax, hemopericardium, diaphragmatic rupture, and major vascular injury ${ }^{(6,7)}$. However, pulmonary complications are often responsible for the morbidity and mortality in these cases $^{(8)}$. Time is critical in managing the injury because there is a high risk of developing one or more life- threatening complications ${ }^{(9)}$. This study aimed to evaluate the relationship between spinal injury and chest damage as well as its significance by analyzing chest injuries accompanying severe blunt spinal trauma.

\section{MATERIALS AND METHODS}

The present study was conducted between October 2017 and October 2020 at the Faculty of Medicine, Çanakkale Onsekiz Mart University. Ethical approval was obtained from the Çanakkale Onsekiz Mart University local ethics committee (IRB number: 2021-01, date: 05.02.2021). Medical records of 88 patients, who were admitted because of severe blunt spinal trauma between October 2017 and October 2020 and whose follow-up and treatment were performed by the authors, were reviewed. A total of 17 patients with incomplete medical data and 16 patients who were presented with penetrating trauma were excluded from the study (Figure 1). The National Emergency X-Radiography Utilization Study method was used

Address for Correspondence: Ümit Ali Malçok, Çanakkale Onsekiz Mart University Faculty of Medicine, Department of Neurosurgery, Çanakkale, Turkey Phone: +90 5336552941 E-mail: umalcok@comu.edu.tr Received: 28.02.2021 Accepted: 09.04.2021

ORCID ID: orcid.org/0000-0002-1272-9654 
in the management of the patients admitted to our hospital (Figure 2) $^{(10)}$.

Fractures were categorized as per the following spinal regions: Cervical (C1-C7), thoracic (T1-T12), and lumbar (L1-L5). The demographic data (age and gender) of the patients, type of injury (falls from height, in-vehicle traffic accidents, blows, nonvehicle traffic accidents, motorcycle accidents), spinal injuries, accompanying thoracic injuries, and length of hospital stay were analyzed. The spinal fracture type, posterior ligamentous complex integrity, injury morphology and neurological status were evaluated using the thoracolumbar İnjury classification and severity score ${ }^{(11)}$. The abbreviated injury scale (AIS) was used to evaluate injuries in the chest area. AIS grades the type and severity of the injury and indicates whether an injury in a particular anatomical region is life-threatening ${ }^{(12)}$. Injuries were scored as minor (AIS 1 or 2 ) or severe (AIS>2) as per the AIS scale. Cases were evaluated using examination results, spinal and spinopelvic bidirectional radiographs, and computed tomography (CT) scans covering the entire spine and thorax region. Imaging modalities were supported by thoracolumbar magnetic resonance imaging (MRI) when there was an unspecified ligamentous injury in CT images or a neurological

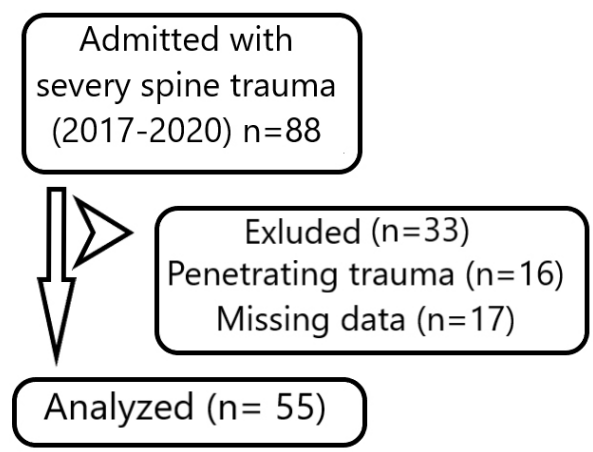

Figure 1. Study flow chart

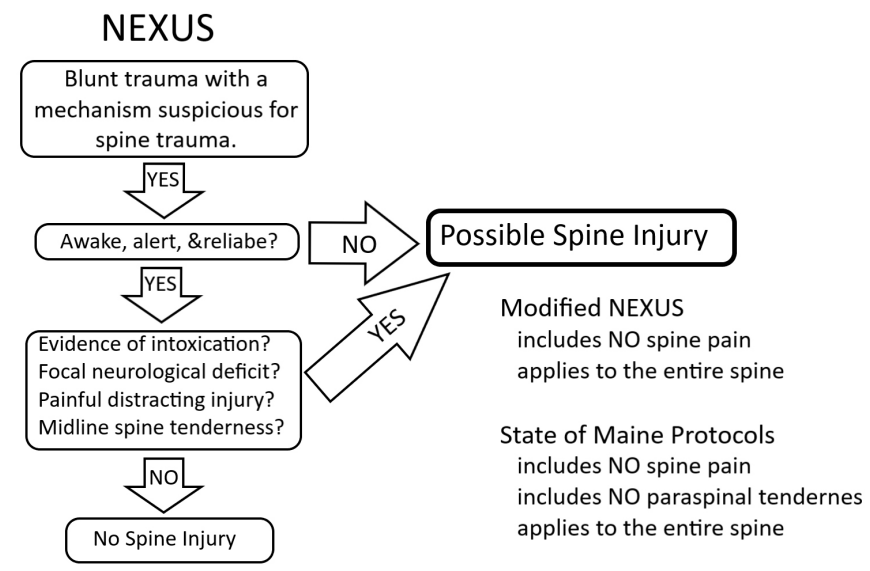

Figure 2. National Emergency X-Radiography Utilization Study method loss ${ }^{(13)}$. The blood analysis protocol routinely used in trauma was applied to all cases.

\section{Statistical Analysis}

Descriptive statistics, such as percentages, mean, and standard deviation, which present the demographic distribution of cases, were calculated. The Kolmogorov-Smirnov normality test was used to decide on the application of a parametric or nonparametric test for the comparison of continuous variables. The Kruskal-Wallis test was used in the comparison analysis of continuous data of the groups. The relationship between categorical variables was analyzed using the crosstab and chisquare tests. When the expected frequencies in most of the cells in the chi-square and crosstab tests were $p<0.05$, the Fisher's exact chi-square test result was considered. The one-sample Kolmogorov-Smirnov test was used to examine a significant difference in a single sample.

\section{RESULTS}

Data of a total of 55 cases [30 (54.5\%) male and 25 (45.5\%) female] were included in the study. The mean age was $58 \pm 15.8$ (range; 22-89, Table 1). Falling from height was the most common cause of trauma in 32 cases (58.2\%) and was significantly more frequent than other causes such as traffic accident, assault, non-vehicle traffic accident, motorcycle accident ( $p<0.001$, Table 2$)$.

The cause of trauma in 17 (60.7\%) cases aged $>60$ years and in $15(46.9 \%)$ cases aged $<59$ was falling from height. There was no statistically significant relationship between the cause of injury and age $(p=0.670)$. Of the severe blunt spinal trauma cases included in the study, 38 (69.1\%) had spinal fractures and 17 (30.9\%) had ligament and other soft tissue damage (Figure 3). Spinal fractures in the thoracic $(n=28 ; 50.9$ frequent compared to cervical and lumbar regions $(p<0.001)$. When considering

Table 1. Demographic distribution of the cases

\begin{tabular}{|c|c|c|c|}
\hline & & $\mathrm{n}$ & $\%$ \\
\hline \multirow{2}{*}{ Sex } & Female & 25 & 45.5 \\
\hline & Male & 30 & 54.5 \\
\hline \multirow{2}{*}{ Age } & $20-59$ & 47 & 49.1 \\
\hline & 60 and above & 28 & 50.9 \\
\hline \multirow{4}{*}{$\begin{array}{l}\text { Spinal fracture } \\
\text { presence and level }\end{array}$} & No fractures & 17 & 30.9 \\
\hline & Cervical & 2 & 3.6 \\
\hline & Thoracal & 28 & 50.9 \\
\hline & Lumbar & 8 & 14.5 \\
\hline \multirow{3}{*}{$\begin{array}{l}\text { Presence of thoracic } \\
\text { injury }\end{array}$} & None & 22 & 40.0 \\
\hline & Chest & 10 & 18.2 \\
\hline & Severe chest & 23 & 41.8 \\
\hline \multirow{4}{*}{$\begin{array}{l}\text { Presence and severity } \\
\text { of neurological loss }\end{array}$} & No deficit & 34 & 61.8 \\
\hline & Quadriplegia & 1 & 1.8 \\
\hline & Paraplegia & 1 & 1.8 \\
\hline & Partial deficit & 19 & 34.5 \\
\hline
\end{tabular}


the distribution of chest injury cases according to the levels of spinal fracture, cases with thoracic vertebral fractures had more severe chest damage, although this difference was not statistically significant $(\mathrm{p}=0.110)$. After neurological evaluation, our cases mostly had a partial neurological deficiency $(n=19$; $34.5 \%$ ), and there was a significant difference between the neurological loss levels of different groups ( $p<0.001$; Table 1$)$. Spinal fractures were significantly more common in severe chest injuries $(p<0.05)$. Cases with spinal fractures and severe chest injuries were significantly higher than those with severe chest injuries but without any spinal fractures $(p<0.05)$. However, cases with severe chest injuries (AIS 3) were higher than cases with minor chest injuries (AIS 1 or 2) among cases with spinal fractures $(p<0.05)$ (Table 3$)$. Thoracic spinal fractures were more common in women $(n=18 ; 85.7 \%)$, but the difference from men $(n=10 ; 58.8 \%)$ was not statistically significant $(p=0.132)$. Likewise, severe chest injury rates were higher in women ( $n=9 ; 39.1 \%)$ than men ( $n=14 ; 69.1 \%)$, but this difference was not statistically significant $(p=0.225)$. When all thoracic injuries were evaluated, rib fractures $(n=10 ; 30.3 \%)$ and pulmonary contusions $(n=6 ; 18.2 \%)$ were observed most frequently. A significant difference was found between the frequency of rib fractures and other chest injuries $(p<0.05)$. By

Table 2. Demographic distribution of trauma mechanisms

\begin{tabular}{lll}
\hline Trauma mechanism & $\mathrm{n}$ & $\%$ \\
\hline Falling from height & $32^{\mathrm{a}}$ & 58.2 \\
\hline Traffic accident & 16 & 29.1 \\
\hline Assault & 4 & 7.3 \\
\hline Non-vehicle traffic accident & 2 & 3.6 \\
\hline Motorcycle accident & 1 & 1.8 \\
\hline $\begin{array}{l}\text { The difference was found to be statistically significant when } \\
\text { "a" was compared with the others. Chi-square, One-Sample } \\
\text { Kolmogorov-Smirnov test was applied and p<0.001 value was } \\
\text { considered significant }\end{array}$ \\
\hline
\end{tabular}

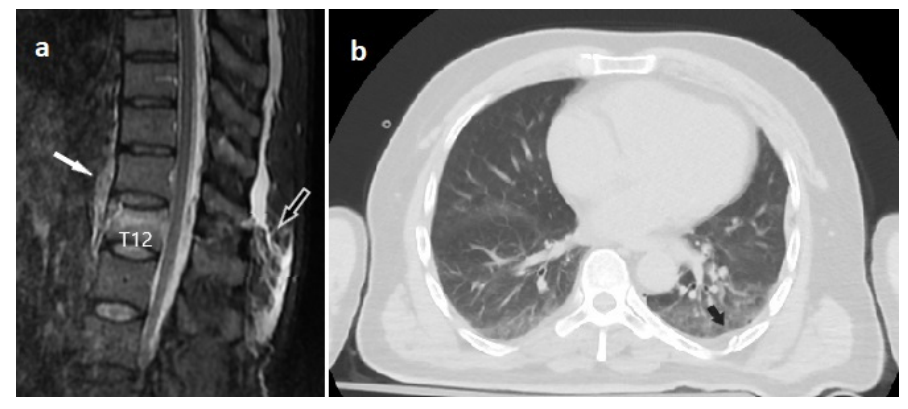

Figure 3. Radiological images obtained in the early post-traumatic period. a) Magnetic resonance image of the sagittal thoracic region made with FSE STIR sequence technique. The area of the hemothorax is shown by the white filled arrow, and the ligament tears and edema area in the thoracic spine area are shown by the black filled arrow. b) Image obtained by computed tomography of the thoracic region. Hemothorax, pulmonary contusion areas and fractured ribs are observed in the area indicated by the black filled arrow contrast, clavicle fracture in six cases and sternum fracture in two cases accompanied other injuries (Table 4).

The follow-up and treatment of 51 (92.7\%) cases were performed by hospitalization, and the mean length of hospital stay was 4.5 \pm 3.4 days (range, $0-15$ ). Four (7.3\%) patients with ligament injury and/or an isolated rib fracture in the spinal region and without any complications, which would prevent their daily activities, were followed up and treated in an outpatient setting. Patients with chest injuries had a longer hospital stay than patients without any chest injury, and the prolongation of this period was statistically significant $(p<0.001)$.

\section{DISCUSSION}

Each year, between 250,000 and 500,000 people worldwide suffer from spinal cord injuries ${ }^{(14)}$. Spinal fractures occur in $4.4 \%$ of patients with general trauma and are particularly frequent in the thoracolumbar region ${ }^{(15)}$. The etiology of $>90 \%$ of spinal injuries include traffic accidents, violence, sports, falls and similar trauma(14). The rib cage provides an important biomechanical protection to the thoracic spine. Therefore, an injury to the thoracic spine means that the cause was a high-energy trauma. Thoracic and lumbar spine fractures are caused by a combination of trauma-producing vectors of force approaching from different directions. Injuries to the upper

Table 3. The relationship between the presence of a fracture in the spine and the severity of the thoracic injury

\begin{tabular}{|c|c|c|}
\hline \multicolumn{3}{|c|}{ Severity of thoracic injury } \\
\hline Vertebrae fracture & Mild & Severe \\
\hline Yes & $2(12.5 \%)^{\alpha \gamma}$ & $14(87.5 \%)^{\alpha \beta}$ \\
\hline No & $8(47.1 \%)^{\gamma \delta}$ & $9(52.9 \%)^{\beta \delta}$ \\
\hline Total & 10 & 23 \\
\hline \multicolumn{3}{|c|}{$\begin{array}{l}\text { There is a significant difference between both " } \alpha \text { ", both " } \beta \text { ", and both } \\
\text { " } \gamma \text { " marked cells }(p<0.05) \text {. It was seen that the difference between the } \\
\text { cells marked with "ळ" was not significant }(p>0.05) \text {. Crosstabs, Pearson } \\
\text { chi-square test was applied and } p<0.05 \text { was considered statistically } \\
\text { significant }\end{array}$} \\
\hline
\end{tabular}

Table 4. Anatomical distribution of injuries in the thoracic region

\begin{tabular}{lll}
\hline Injured thoracic region & $\mathrm{n}=33$ & $\%$ \\
\hline Rib fracture & $10^{\mathrm{a}}$ & 30.3 \\
\hline Pulmonary contusion & 6 & 18.2 \\
\hline Pneumothorax & 2 & 6.1 \\
\hline Hemothorax & 1 & 3.0 \\
\hline Rib fracture with hemothorax & 3 & 12.1 \\
\hline Rib fracture with pneumothorax & 4 & 15.2 \\
\hline Rib fracture with pulmonary contusion & 3 & 9.1 \\
\hline Multiple rib fractures & 2 & 6.1 \\
\hline
\end{tabular}

Cases with more than one thoracic injury were included. The difference was found to be statistically significant when "a" was compared with the others. chi-square, One-Sample Kolmogorov-Smirnov test was applied $p<0.05$ was considered statistically significant 
or middle thoracic spine are often caused by a high-energy trauma, such as a motor vehicle accident ${ }^{(16)}$. In our study, falling from height was the most common cause of trauma with 32 (58.2\%) cases, and it was significantly higher than other causes of trauma $(p<0.001)$. Because agricultural activities are intense in the area where our hospital is located, falling from trees during harvests are common. Older adults presenting with trauma should be examined in more detail because the risk of spinal fractures increases with older age. These patients are particularly susceptible to traumatic spinal injury because of many factors, such as changes in bone quality with aging, medications, and increased prevalence of spinal stenosis and spinal diseases. Because of the increased risk of fractures, the rate of complications is higher in traumas suffered by older adults. Tissue damage due to trauma increases with age $\mathrm{e}^{(17)}$. Adults aged $>60$ years suffer from graver spinal injuries than younger patients. In older adults, traumas due to falls from height occur more often, and fracture formation is the result of an age-related decrease in the load-bearing capacity of the bone. Because $50.9 \%$ of our cases were aged $\geqslant 60$ years, the frequency of thoracic injuries accompanying spinal fractures was quite high in our study.

A chest tissue injury missed by radiographic and physical examinations may lead to permanent physiological and neurological losses in patients ${ }^{(16,18)}$. To prevent such situations, it is necessary to use trauma algorithms and investigate carefully whether there is a chest injury in patients with spinal fractures, as demonstrated in our study. Damages to the spinal cord, soft tissues, and ligaments, that developed after spinal trauma, were detected by patient MRIs. This imaging method is extremely helpful in detecting damage to the intervertebral discs, ligaments, vascular structures, and the spinal cord, and for making differential diagnosis ${ }^{(16,19)}$. Some studies examined injuries accompanying spinal fractures and reported that extremity and cranial injuries were common ${ }^{(20,21)}$. However, it is well known that damage to the spine, ribs, and intrathoracic structures is frequently overlooked. Rib fractures are a highly painful and disabling type of injury commonly observed among trauma patients, and many studies have shown that the unexpected frequency of rib fractures has a negative impact on patients ${ }^{(22,23)}$. Leucht et al. ${ }^{(20)}$ reported that thoracic injuries accompanied $18.5 \%$ of patients with spinal fractures and was the third most common injury accompanying vertebral fractures. Rib fractures are usually associated with pulmonary contusions that significantly increase pulmonary morbidity in patients with multiple traumas ${ }^{(24,25)}$. Thoracic pathologies accompanying vertebral fracture cases included in our study were mostly rib fractures and pulmonary contusions. In severe spinal trauma, the thoracic spine is affected more, and the fracture risk is higher than in the other spinal regions ${ }^{(26)}$. Likewise, in our study, thoracic fracture was significantly higher than cervical and lumbar $(p<0.001)$. Neurological involvement following trauma in our cases was mostly at the level of partial neurological deficit $(n=19 ; 34.5 \%$; $p<0.001)$.
Patients with stable thoracolumbar fracture without neurological loss and who are treated conservatively show better results than surgically treated patients ${ }^{(27)}$. We applied conservative methods to the patients with a partial neurological loss in our study, and no additional neurological loss developed during follow-up. The length of hospital stay was particularly prolonged in patients aged $>50$ years with multiple traumas accompanied by chest injuries ${ }^{(28)}$. In our study, 33 patients who were followed up for chest injuries, stayed in the hospital longer than patients without any chest injury $(p<0.001)$.

\section{Study Limitations}

Our study has some limitations: The study was retrospective in nature and the number of cases was small. By contrast, we believe that the study provides valuable clinical data, particularly to emergency service providers, by contributing to the reduction of morbidity and mortality in such cases.

\section{CONCLUSION}

Chest injuries, which are the most important complications that accompany spinal injuries and threaten life, should be considered primarily in patients with multiple traumas. This risk is further increased in cases with thoracic spinal fractures. Coexistence of spine and chest injuries increases in the elderly patient group, especially in cases of falling from height. In our study, we concluded that the majority of injuries in the spine were thoracic vertebral fractures and these cases had a high risk of neurological loss. Imaging techniques, such as MRI and $\mathrm{CT}$, should be among the diagnostic and follow-up modalities in addition to clinical evaluation in accordance with trauma protocols for diagnosing pulmonary and vascular complications as well as thoracic wall pathologies.

\section{Ethics}

Ethics Committee Approval: Ethical approval was obtained from the Çanakkale Onsekiz Mart University, Ethical Board of Clinical Studies (IRB number: 2021-01, date: 05.02.2021).

Informed Consent: Permission to use medical records for clinical studies were present on the routine patient consent forms received before the operation.

\section{Authorship Contributions}

Concept: H.O.K., Ü.A.M., Design: H.O.K., Ü.A.M., Data Collection or Processing: Ü.A.M., Analysis or Interpretation: H.O.K., Ü.A.M., Literature Search: H.O.K., Writing: H.O.K., Ü.A.M.

Conflict of Interest: The authors declare that they have no conflict of interest.

Financial Disclosure: The authors declared that this study received no financial support.

\section{REFERENCES}

1. National Trauma Data Bank Annual Report 2007. Last Accessed Date: 13.03.2016. Available from: https://viaaerearcp.files.wordpress. com/2018/02/atls-2018.pdf. 
2. Pirouzmand F. Epidemiological trends of spine and spinal cord injuries in the largest Canadian adult trauma center from 1986 to 2006: Clinical article. J Neurosurg Spine. 2010;12:131-40.

3. Cason B, Rostas J, Simmons J, Frotan MA, Brevard SB, Gonzalez RP. Thoracolumbar spine clearance: clinical examination for patients with distracting injuries. J Trauma Acute Care Surg. 2016;80:125-30.

4. Pape HC, Giannoudis PV, Krettek C, Trentz O. Timing of fixation of major fractures in blunt polytrauma: Role of conventional indicators in clinical decision making. J Orthop Trauma. 2005;19:551-62.

5. Rajasekaran S, Kanna RM, Shetty AP. Management of thoracolumbar spine trauma An overview. Indian J Orthop. 2015;49:72-82.

6. Marco RA, Kushwaha VP. Thoracolumbar burst fractures treated with posterior decompression and pedicle screw instrumentation supplemented with balloon-assisted vertebroplasty and calcium phosphate reconstruction. J Bone Jt Surg. 2009;91:20-8.

7. Benson DR, Burkus JK, Montesano PX, Sutherland TB, McLain RF. Unstable Thoracolumbar and Lumbar Burst Fractures Treated with the AO Fixateur Interne. J Spinal Disord. 1992;5:335-43.

8. Aarabi B, Harrop JS, Tator CH, Alexander M, Dettori JR, Grossman RG, et al. Predictors of pulmonary complications in blunt traumatic spinal cord injury. J Neurosurg Spine. 2012;17:38-45.

9. Student Course Manual ATLS $®$ Advanced Trauma Life Support $®$. 2018. Available from: https://www.facs.org/-/media/files/qualityprograms/trauma/ntdb/ntdb-annual-report-2016.ashx. Last Accessed Date: 02.10.2020.

10. Hoffman JR, Wolfson AB, Todd K, Mower WR. Selective cervical spine radiography in blunt trauma: Methodology of the national emergency X-radiography utilization study (NEXUS). Ann Emerg Med. 1998;32:461-9.

11. Lee JY, Vaccaro AR, Lim MR, Oner FC, Hulbert RJ, Hedlund R, et al. Thoracolumbar injury classification and severity score: a new paradigm for the treatment of thoracolumbar spine trauma. J Orthop Sci. 2005;10:671-5.

12. Ramzy A, Karmy-Jones R, Long W. Chest trauma: the role of ınjury severity scoring. Curr Respir Med Rev. 2015;11:3-7.

13. Bozzo A, Marcoux J, Radhakrishna M, Pelletier J, Goulet B. The role of magnetic resonance imaging in the management of acute spinal cord injury. J Neurotrauma. 2011;28:1401-11.

14. Spinal cord injury. World Health Organization. Last Accessed Date: 09.10.2020. Available from: https://www.who.int/news-room/ fact-sheets/detail/spinal-cord-injury.

15. Cooper C, Dunham CM, Rodriguez A. Falls and major injuries are risk factors for thoracolumbar fractures: Cognitive impairment and multiple injuries impede the detection of back pain and tenderness. J Trauma. 1995;38:692-6.
16. van Den Hauwe L, Sundgren PC, Flanders AE. Spinal Trauma and Spinal Cord Injury (SCI). 2020 Feb 15. In: Hodler J, Kubik-Huch RA, von Schulthess GK, editors. Diseases of the Brain, Head and Neck, Spine 2020-2023: Diagnostic Imaging [Internet]. Cham (CH): Springer; 2020. Chapter 19.

17. Stubbs B, Binnekade T, Eggermont L, Sepehry AA, Patchay S, Schofield P. Pain and the risk for falls in community-dwelling older adults: Systematic review and meta-analysis. Arch Phys Med Rehabil. 2013;95:175-87.

18. Sheridan R, Peralta R, Rhea J, Ptak T, Novelline R. Reformatted visceral protocol helical computed tomographic scanning allows conventional radiographs of the thoracic and lumbar spine to be eliminated in the evaluation of blunt trauma patients. J Trauma. 2003;55:665-9.

19. Sliker CW, Mirvis SE, Shanmuganathan K. Assessing cervical spine stability in obtunded blunt trauma patients: review of medical literature. Radiology. 2005;234:733-9.

20. Leucht P, Fischer K, Muhr G, Mueller EJ. Epidemiology of traumatic spine fractures. Injury. 2009;40:166-72.

21. Pirouzmand F. Epidemiological trends of spine and spinal cord injuries in the largest Canadian adult trauma center from 1986 to 2006: Clinical article. J Neurosurg Spine. 2010;12:131-40.

22. Shelat VG, Eileen S, John L, Teo LT, Vijayan A, Chiu MT. Chronic pain and its impact on quality of life following a traumatic rib fracture. Eur J Trauma Emerg Surg. 2012;38:451-5.

23. Ziegler DW, Agarwal NN. The morbidity and mortality of RIB fractures. J Trauma. 1994;37:975-9.

24. Battle CE, Hutchings $\mathrm{H}$, Evans PA. Risk factors that predict mortality in patients with blunt chest wall trauma: A systematic review and metaanalysis. Injury. 2012;43:8-17.

25. Wang Hw, Xiang Q, Li C qing, Zhou Y. Traumatic vertebral fractures with concomitant fractures of the first rib. Orthop Surg. 2013;5:100-4.

26. Tee JW, Chan PCH, Gruen RL, Fitzgerald MCB, Liew SM, Cameron $\mathrm{PA}$, et al. Early predictors of mortality after spine Trauma. Spine. 2013;38:169-77.

27. Anderson PA. Long-term results still favor nonoperative treatment of stable thoracolumbar burst fractures: commentary on an article by Kirkham B. Wood, MD, et al.: "Operative compared with nonoperative treatment of a thoracolumbar burst fracture without neurological deficit. A prospective randomized study with follow-up at sixteen to twenty-two years". J Bone Joint Surg Am. 2015;97:e4. doi: 10.2106/JBJS.N.01092.

28. Chrysou K, Halat G, Hoksch B, Schmid RA, Kocher G]. Lessons from a large trauma center: impact of blunt chest trauma in polytrauma patients-still a relevant problem? Scand J Trauma Resusc Emerg Med. 2017;25:42. 